\title{
Bilinguals apply language-specific grain sizes during sentence reading
}

Egan, Ciara; Oppenheim, Gary; Saville, Christopher; Moll, Kristina; Jones, Manon

\section{Cognition}

\author{
DOI: \\ 10.1016/j.cognition.2019.104018
}

Published: 01/12/2019

Peer reviewed version

Cyswllt i'r cyhoeddiad / Link to publication

Dyfyniad o'r fersiwn a gyhoeddwyd / Citation for published version (APA):

Egan, C., Oppenheim, G., Saville, C., Moll, K., \& Jones, M. (2019). Bilinguals apply languagespecific grain sizes during sentence reading. Cognition, 193, [104018].

https://doi.org/10.1016/j.cognition.2019.104018

\footnotetext{
Hawliau Cyffredinol / General rights

Copyright and moral rights for the publications made accessible in the public portal are retained by the authors and/or other copyright owners and it is a condition of accessing publications that users recognise and abide by the legal requirements associated with these rights.

- Users may download and print one copy of any publication from the public portal for the purpose of private study or research.

- You may not further distribute the material or use it for any profit-making activity or commercial gain

- You may freely distribute the URL identifying the publication in the public portal ?
}

Take down policy

If you believe that this document breaches copyright please contact us providing details, and we will remove access to the work immediately and investigate your claim. 


\title{
Bilinguals apply language-specific grain sizes during sentence reading
}

\author{
Ciara Egan', Gary Oppenheim ${ }^{12}$, Christopher Saville1, Kristina Moll ${ }^{3}$, Manon Wyn \\ Jones $^{1}$
}

${ }^{1}$ School of Psychology, Bangor University, UK.

${ }^{2}$ Department of Psychology, Rice University, Houston, TX, USA.

${ }^{3}$ Department of Child and Adolescent Psychiatry, Psychosomatics and Psychotherapy,

Ludwig-Maximilian University, Munich, Germany.

\author{
Dr Manon Wyn Jones, \\ School of Psychology \\ Adeilad Brigantia \\ Penrallt Road \\ Bangor University \\ Bangor
}

Address for correspondence:

LL57 2AS

Tel: 01248382319

Email: manon.jones@bangor.ac.uk

Dr Gary M. Oppenheim,

School of Psychology

Adeilad Brigantia

Penrallt Road

Bangor University

Bangor

LL57 2AS

Tel: 01248388838

Email: g.m.oppenheim@bangor.ac.uk

\section{Acknowledgments}

MWJ is an associate member of the Welsh National College (colegcymraeg.ac.uk). We thank Joshua Payne for his helpful comments on the manuscript.

\section{Disclosure of interest}

The authors report no conflicts of interest. 


\section{Abstract}

Languages differ in the consistency with which they map orthography to phonology, and a large body of work now shows that orthographic consistency determines the style of word decoding in monolinguals. Here, we characterise word decoding in bilinguals whose two languages differ in orthographic consistency, assessing whether they maintain two distinct reading styles or settle on a single 'compromise' reading style. In Experiment 1, WelshEnglish bilinguals read cognates and pseudowords embedded in Welsh and English sentences. Eye-movements revealed that bilinguals dynamically alter their decoding strategy according to the language context, including more fixations during lexical access for cognates in the more consistent orthography (Welsh) than in the less consistent orthography (English), and these effects were specific to word (as opposed to pseudoword) processing. In Experiment 2, we compared the same bilinguals' eye movements in the English sentence reading context to those of monolinguals'. Bilinguals' eye-movement behaviour was very similar to monolinguals' when reading English, suggesting that their knowledge of the more consistent orthography (Welsh) did not alter their decoding style when reading in English. This study presents the first characterisation of bilingual decoding style in sentence reading. We discuss our findings in relation to connectionist reading models and models of bilingual visual word recognition. 


\section{Introduction}

Rapidly converting letters into sounds is a hallmark of skilled reading across all languages, yet the consistency of letter-sound mappings will determine how readers achieve it in each individual language. For inconsistent orthographies such as English, readers learn to recognize words using larger-unit grain sizes, such as onsets, rimes, and whole words. For consistent orthographies, representing most other European languages (e.g., German, Italian, Spanish, Welsh), readers typically rely more on smaller-unit processing (cf. Caravolas et al., 2013; Rau, Moll, Snowling, \& Landerl, 2015). Such conflicting reading strategies raise the important theoretical question of how letter-sound correspondence is represented and implemented in people who read multiple languages. In this paper, we use eye-tracking to examine whether or not bilingual reading systems dynamically adapt to current language contexts, with synergistic implications for current models of reading and bilingual word recognition (e.g., Seidenberg \& McClelland, 1989; Dijkstra \& van Heuven, 2002).

Connectionist reading models (Harm \& Seidenberg, 1999; Manis et al., 1999; Seidenberg \& McClelland, 1989) characterize word reading skill as a mapping from letters to phonological forms, gradually acquired via statistical learning. Take, for example, Seidenberg and McClelland's (1989) word recognition model, which maps orthography to phonology via a layer of hidden units. This reading system learns, through backpropagation of error, to adjust grapheme-phoneme correspondences to the vagaries of the orthographical properties of English, for example, on the basis of regularity, consistency, and so-called 'strange' words, with very little discernable letter-sound patterning (such as aisle). Based on knowledge of all known words in the inconsistent English orthography, then, the system can adapt its decoding approach, depending less on simple or abstract grapheme-to-phoneme 'rules' and more on interpolating between the grapheme-to-phoneme mappings for orthographically similar 
words (e.g., LINT may be pronounced by analogy to known words with similar rime pronunciations: MINT, STINT, HINT, etc.). Assuming that reading any given word in this system represents the sum of experience with all known words in a given language, it is plausible that the same reading system, when exposed to a more consistent orthography that does not require the same scope for interpolation, may instead learn to map between orthographic and phonological units via smaller grapheme-to-phoneme units (e.g. bigrams instead of trigrams). Consistent with this account, orthographic neighbourhood size appears to exert a greater influence on reading in inconsistent languages (Ziegler, Perry, Ma-Wyatt, Ladner, \& Shulte-Körne, 2003; Wimmer \& Goswami, 1994; Ziegler, Perry, Jacobs, \& Braun, 2001) reflected, for example, in the use of lexical analogies at the rime level. Readers of consistent orthographies, on the other hand, rely more on smaller orthographic units, in which word recognition is slower for longer words (Ellis \& Hooper, 2001; Goswami, Gombert \& Fraca de Barrera, 1998).

This rationale underpins psycholinguistic grain size theory (cf. Ziegler \& Goswami, 2005), in which language-specific decoding strategies reflect the graphemic unit at which phonological consistency is maximised (e.g., Davies, Cuetos, \& Glez-Seijas, 2007; Ziegler \& Goswami, 2005; Ziegler et al., 2001; Rau et al., 2015). Moreover, variation in decoding strategy is assumed to be more than an emergent property of orthographic learning, or an interesting yet redundant epiphenomenon. Children acquiring an inconsistent orthography tend to do so more slowly than those acquiring a consistent orthography (cf. Caravolas et al., 2012; Marinus, Nation, \& deJong, 2015), are more likely to make nonword reading errors (Landerl, 2000; Goswami, Ziegler, Dalton, \& Schneider, 2003), and tend to rely more on whole-word lexical phonology (Ellis et al., 2004; Wimmer \& Goswami, 1994), consistent with reading via larger grain size mappings. More direct indications of cross-linguistic grain size differences 
can also be revealed by eye tracking measures. For example, Rau et al. (2015) compared groups of German (more consistent) and English (less consistent) children and adults as they read sentences containing cognates - words with shared lexical representations in both languages - (e.g., problem). Compared to their English counterparts, German children showed longer gaze durations as a function of word length, and German adults showed longer gaze durations for nonwords (derivatives of the cognates), purported to reflect a serial approach to reading. Thus, a well-documented literature attests to systematic differences between readers' grain-sizes (Duncan, Seymour, \& Hill, 1997; Goswami, Ziegler, Dalton, \& Schneider, 2001), as a function of their language's orthographic consistency.

What is less known, however, is how grapheme-phoneme mapping is achieved by people who read multiple languages: literate bilinguals. Bilinguals often read languages with quite different orthographic to phonological mappings. For instance, Welsh-English bilinguals must learn that the grapheme 'dd' maps to /ð/ in Welsh, but an ambisyllabic /d/ or /t/ in English. Welsh orthography, moreover, is more consistent than that of English, implying that its readers should read with a smaller grain size than those of English. But interestingly, all contemporary Welsh readers also read and speak English to native-level proficiency. Welsh and English are also spoken and read side-by-side in certain regions of North Wales. So, if reading systems adjust to accommodate the statistical regularities of a target language, then how might they adjust to differences in these patterns between languages? Would they incorporate all orthographic forms into a single system - for instance, regularity effects would be based on some hybrid of the languages - or would they somehow functionally separate them by language, processing the words of each language in a language-specific way? A key theoretical question, therefore, is how the reading models currently used to explain orthography to phonology mappings can account for the case of bilingualism. 
The Bilingual Interactive Activation model (BIA; Dijkstra \& van Heuven, 1998) and its successor, the BIA+ (Dijkstra \& van Heuven, 1998; Dijkstra, van Heuven, \& Grainger, 1998; Dijkstra \& van Heuven, 2002) represent bilingual extensions of McClelland and Rumelhart's (1981) monolingual Interactive Activation model of word recognition, primarily distinguished by their addition of localist nodes for each of a bilinguals' languages. Both models specify the bottom-up nature of bilingual visual word recognition, in which bilingual lexical access is non-selective with regards to language (cf Kroll \& Ma, 2017 for a review), a tenet that is more firmly instantiated in the BIA+ model, which omits top-down connections from the language nodes, thus preventing language-node activation from modulating lexical activation. This revised claim is, however, at odds with accumulating evidence that the initially language non-selective mechanism can be constrained by language-specific cues, such as distinctive bigram frequencies (Casaponsa, Carreiras, \& Duñabeitia, 2014, 2015, 2016), or the larger language context in which a word appears (Altarriba, Bauer, \& Benvenuto, 1996; Declerck, Snell, \& Grainger, 2018; Elston-Güttler, Paulmann, \& Kotz, 2002; Libben \& Titone, 2009; but see van Assche, Drieghe, Duyck, Waelvert, \& Hartsuiker, 2011).

If we begin with the BIA+ as our framework, we might initially assume that grain size mapping in bilinguals is language non-selective. That is, the weights of orthographic and phonological connections and dynamic interactions between the two reflect all known orthographic combinations in both languages together. The resulting reading strategy would therefore comprise a hybrid decoding strategy. This view is encapsulated in the recent 'grain size accommodation' hypothesis (Lallier \& Carreiras, 2017), in which the features of each orthography are claimed to merge and influence each other, resulting in a reading profile that 
does not fit the monolingual reading profile of either language. For example, in the case of English-Spanish bilingualism, representing one inconsistent and one consistent orthography, the bilingual should show smaller grain size reading in English compared with that typically observed in monolingual readers of English, and larger grain size reading in Spanish compared with that typically observed in monolingual readers of Spanish. Lallier, Tainturier, Savill and Thierry (2013) found evidence to support this account in an event related potential (ERP) study, in which Welsh-English bilinguals were asked whether a target letter appeared in a nonword displayed at fixation, or in an English word presented immediately prior to fixation. Bilinguals processed less information to the right of fixation compared with a monolingual English group, which the authors interpret as a covert influence from the consistent (Welsh) orthographic reading style on English word reading, reflecting a smaller window of visual attention. In a similar vein, Spanish-Basque bilingual children with two orthographically consistent languages showed smaller grain size decoding strategies in Basque, compared to the case in French-Basque children, with one inconsistent and one consistent orthography (Lallier et al., 2015).

However, given recent evidence that top-down contextual influences can modulate bilingual visual word recognition (e.g., Declerck, Snell, \& Grainger, 2018) a plausible alternative account is one in which bilinguals can adapt their decoding strategies to the language in which they are currently reading, using larger grain sizes when reading less consistent orthographies. Some empirical evidence already supports this contention: In early FrenchGerman bilinguals, a French or German context preceding a test phase prompted single word reading in which fixations were made closer to the center of words in the orthographically inconsistent context (French) than the orthographically consistent context (German; de León Rodríguez et al., 2016). Similarly, a study testing French-Spanish bilingual children 
suggested a preference for smaller grain-size reading in the shallow orthography: whereas French produced superior word over pseudow ord reading accuracy, suggesting a large-grain strategy, more similar accuracy for words and pseudowords in Spanish suggested a smaller grain strategy (Lallier, Valdois, Lassus-Sangosse, Prado and Kandel, 2014). However, none of these studies have compared eye movements during reading in more naturalistic sentence contexts, so it has not yet been directly tested whether more natural language contexts actually change bilinguals' online decoding strategies.

\subsection{The current study}

In this study, we investigated whether bilingual reading systems dynamically adjust to language contexts, implementing larger and smaller reading grains as a function of the language sentence context. To this end, we used eye-tracking to examine word decoding in the context of Welsh and English sentence reading for early, fluent Welsh-English bilinguals, a highly interesting and unique demographic of bilinguals, for whom a consistent (Welsh $\left.{ }^{1}\right)$ and inconsistent (English) orthography are both acquired at a very early age (typically 4-5 years old for Welsh, 6-7 years old for English). We conducted two experiments in which the objectives were to 1.) establish whether bilinguals' grain size processing is modulated by language context and 2.) whether bilinguals' grain size in one language is permanently altered by knowledge of the orthotactic properties of the other language. To this end, Experiment 1 examined how bilinguals decode words in Welsh and English context sentences, whilst Experiment 2 examined whether bilinguals' and monolinguals' word decoding differ in English sentence contexts. To exert maximum experimental control over

\footnotetext{
${ }^{1}$ The Welsh orthography contains mappings between graphemes and phonemes that are extremely consistent (Ball \& Jones, 1984, Ellis \& Hooper, 2001), with only some inconsistencies in vowel sounds (for example, the graphemes $/ \mathrm{u} / \mathrm{and} / \mathrm{y} /$, each of which corresponds to multiple phonemes). Nevertheless, the orthography of Welsh is very different from the case of English, where vowel consistency is estimated at only 51\% (Treiman, 1995).
} 
the linguistic input, our target words comprised Welsh-English cognates and pseudowords, thereby comparing lexical and sub-lexical processing, respectively. Thus, if language context indeed alters grain size, we can assess whether it exerts general effects on pronounceable orthographic sequences with common bigram frequencies (irrespective of lexicality, i.e. including pseudowords), or specifically alters grain size processing for well-established orthographic combinations (specific to known words).

\section{Experiment 1}

In Experiment 1, bilingual participants read aloud English and Welsh sentences (translation equivalents), containing English/Welsh cognate words (e.g., normal), or matched 'pseudowords' that were orthotactically and phonologically legal in both languages (e.g., nostal), as we tracked several aspects of their eye movements (see Appendix A for the full stimulus list). This paradigm simultaneously allowed us to determine, for the first time, how reading words in a language-specific sentence context influences bilinguals' decoding style, whilst exerting maximal control over bottom-up processes: cognates are almost fully overlapping in terms of their cross-linguistic orthographic, phonological and semantic properties. Using this paradigm, we examined whether bilinguals implemented a word decoding strategy using larger or smaller grain sizes as a function of the language context.

Sentence reading studies typically distinguish between early and late indicators of word recognition (cf. Rayner, 1998). Early indicators include eye movement behaviours showing the initial encounter on a target word ('first pass', including the eye's initial landing position, the first fixation duration and gaze duration), and are therefore considered to reflect predictive processes arising from the sentence context and lexical access, before more 
information is encountered downstream. The duration of their first fixation within the word, and the duration and number of subsequent first-pass fixations, are intercorrelated measures reflecting the inital uptake of information for lexical access (Pollatsek \& Rayner, 1990; Pynte, 1996; Rayner \& Pollatsek, 1987). Late processes emerge in measures that take into account 'second pass' measures, which include return fixations to the word (regression path duration), and are bundled together with the earlier processes in summary measures (e.g., total fixation count and duration); these are considered to reflect semantic integration and reanalysis of the word in light of the broader sentence meaning.

In this study, we are primarily concerned with the units of graphemic processing involved in lexical access, so our key measure is the number of fixations made on the target item during first pass (for use of this measure in cross-linguistic contexts, see de León Rodríguez et al., 2016; Gangl et al., 2018). If orthographically consistent sentence contexts generally evoke smaller grain-size mapping, then readers should execute more fixations on the same orthographic strings when they occur in Welsh sentence contexts than when they occur in English sentence contexts, regardless of whether the string is a real word or a pseudoword. However, if such variation in grain-size mapping specifically reflects readers' repeated exposures to certain orthographic combinations corresponding to lexical entries (i.e., statistical learning of specific words), then we would expect readers' fixations to differ between the languages more for real words than for pseudowords (i.e. a language-bylexicality interaction). Note that while we have framed these predictions in terms of first-pass fixation counts, that measure is highly intercorrelated with other first-pass measures and summary measures (cf. Rayner, 1998). Following standard eyetracking reporting conventions, we also report these other measures but do not derive independent predictions for them. 
More exploratively, if language effects on decoding also affect later stages of word recognition, we expected that smaller grain-size mapping should confer more regressions to the target word.

\subsection{Methods}

\subsubsection{Participants}

Forty-eight Bangor University students $(\mathrm{n}=48$; female $=37)$ were included in the analyses, who self-reported that they were fluent Welsh-English bilinguals, and used no other languages. One additional participant's dataset was excluded from analysis, due to a technical error in data recording. Participants rated their daily usage of Welsh (speaking, reading and writing) at $49 \%$ ( $\pm 2 \% \mathrm{SD}$ ) on average. Mean age for learning to speak English was $2 \pm 2.3$ years. All participants received the first two years of their primary education in Welsh, before being taught to read in English from the age of seven. All participants had normal or corrected-to-normal vision.

\subsubsection{Materials and design}

Target cognate words had a mean Zipf frequency of $4.14 \pm 0.57$ (SD) in Welsh and $4.15 \pm$ 0.54 (SD) in English, as calculated by the Cronfa Electroneg o'r Gymraeg (CEG; Welsh, Ellis, O’Dochartaigh, Hicks, Morgan \& Laporte, 2001) and CELEX (English) databases, respectively (Baayen, Piepenbrock \& Gulikers, 1995). Zipf values were calculated based on the method outlined by van Heuven et al (2014). A Mann-Whitney U test showed no significant difference for cognate frequency between the two languages $(\mathrm{U}=1799, p=.996)$. Pseudowords were created from the cognates by using Pseudo (version 2.07; Van Heuven, 2016) to alter one grapheme per syllable of the original word. To extract bigram frequencies 
based on the Cronfa and CELEX databases, Welsh and English cognates and pseudowords were entered into Lingua (Language-Independent Neighbourhood Generator of the University of Alberta; Westbury, Hollis \& Shaoul, 2007). Extracted frequencies controlled for bigram position and word length, and represented average bigram token frequencies across the whole word. Cognate words had a median log bigram frequency of $2.82 \pm .36$ (IQR) in Welsh and $2.73 \pm .61$ (IQR) in English. Pseudowords had a median bigram frequency of $2.73 \pm .46(\mathrm{IQR})$ in Welsh, and $2.79 \pm .46(\mathrm{IQR})$ in English. A Kruskall-Wallis test showed no significant differences, $\chi 2(3)=2.23, \mathrm{p}=.526$.

Cognates and pseudowords were presented in the context of English and Welsh sentences (see Appendix A), which we created to be translation equivalents with similar word order (e.g. 'The children went to see the clown and he was very funny'/ Fe aeth y plant [The children went] $i$ weld $y$ clown [to see the clown] ac roedd o'n ddoniol iawn [and he was very funny]). Each sentence contained one target word, which was never presented as the first or last word of the sentence. Filler sentences, with a grammatical structure similar to the experimental sentences, but without cognates or pseudowords, comprised $33.3 \%$ of all trials. Stimulus presentation was counterbalanced to avoid target repetition, such that each participant saw an equal number of stimuli in each language and condition, but if a participant saw the English version of a sentence with the cognate, they would see the Welsh version with the pseudoword, and vice versa (e.g. 'It's quite normal to sunbathe in July'/'Mae'n beth eithaf nostal i dorheulo yn mis Gorffennaf’).

\subsubsection{Procedure}

Eye movements were recorded from the participants' right eye using an Eyelink 1000 desktop-mounted eye tracker. The experiment was preceded by a 9-point calibration. 
Sentences were then presented in the centre of a $60 \mathrm{~cm}$ wide monitor (60 Hz refresh rate), in black 20-point Courier New on a white background, with the participant seated $60 \mathrm{~cm}$ from the screen.

At the beginning of each trial, participants fixated a small black circle, for drift correction (See Figure 1). The experimenter then initiated the trial, at which point the sentence appeared (the drift correct location ensured that the eyes initially fixated the first letter of the first word for each sentence). Welsh / English sentence presentation was blocked, whilst cognate / pseudoword sentence presentation within these blocks was pseudorandomised. Each block comprised 90 items (60 target sentences, 30 filler sentences), interspersed with a break.

Figure 1. Schematic of the trial procedure.

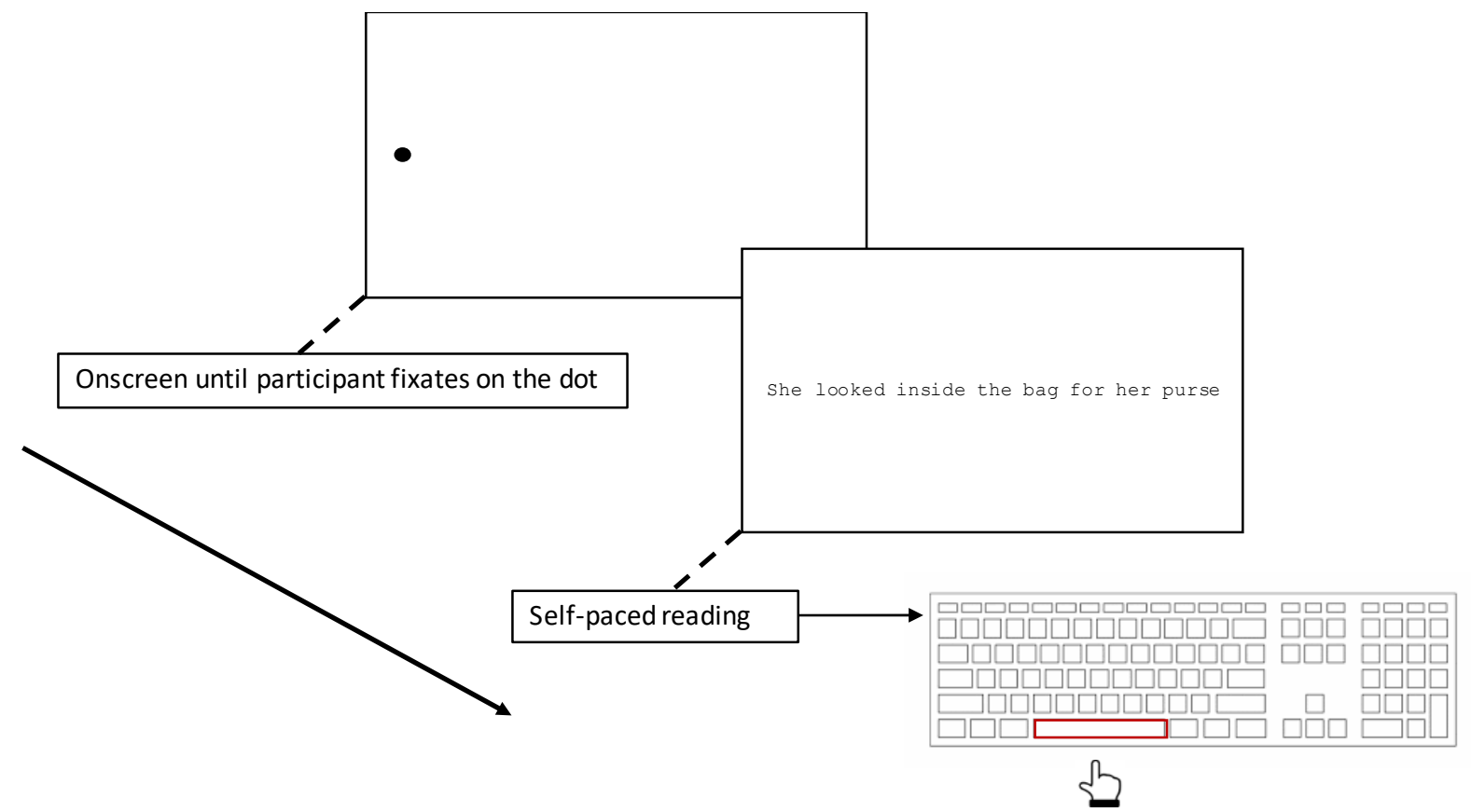

2.2 Results \& Discussion 
Track losses, skipped items and programming errors were excluded (7\%). Log-transformed timing data were analysed via linear mixed effects regression (Bates, Maechler, Walker, \& Bolker, 2016) for R v3.3.2 (R Development Core Team, 2016) with parsimonious random effects structures (Bates, Kliegl, Vasishth, \& Baayen, 2015), omitting correlations between random effects to facilitate convergence and using the Wald approximation to transform $t$ values into z scores. Count data were analysed via generalised linear mixed effects regression, assuming Poisson distributions, and again using parsimonious random effects structures. Each model includes two fixed effects, both contrast-coded and centered, plus their interaction: (1) Language Context $\{$ English $=-0.5$, Welsh $=0.5\}$ (2) Lexicality $\{$ Cognate $=-0.5$, Pseudoword $=0.5\}$.

The results of these analyses are given in Table 2 and depicted in Figure 2 (also comparing bilingual data to the monolingual results from Experiment 2). For the measure of primary theoretical interest, first pass fixation count, bilinguals produced generally more fixations on pseudowords than cognates. They also fixated stimuli more often when they occurred in Welsh contexts than English contexts, and a significant Language X Lexicality interaction effect shows that this main effect is driven by the cognates rather than the pseudowords. As illustrated in our primary measure - first fixation count - in Figure 2(a), the difference between languages is most evident for real words. Other measures of lexical access - first fixation and first pass gaze duration - patterned similarly across languages (Figure 2b\&c). Finally, eye movement measures typically associated with later linguistic processes regression path, total fixation time, and total fixation count - showed a pattern consistent with the early lexical processing measures (Figure 2e-g). Generally, target words in Welsh sentences were associated with longer processing times and more fixations, but Language by 
Lexicality interactions suggest that language context exerted a particular influence on cognates, possibly reflecting cascading lexical processes.

Although the above analyses include a few items where the stimulus orthography differed slightly between languages (e.g., 'film' in English vs. 'ffilm' in Welsh), restricting the analyses to exact orthographic matches across language (highlighted in Appendix A), yields equivalent results (see supplementary analysis section).

Our overall pattern of results therefore suggest that bilinguals adapt grain size to fit the language context when reading known orthographic sequences. In order to examine whether bilinguals predictively apply language-specific grain size, we conducted a post hoc analysis of landing position on the cognate item in Welsh and English contexts (pseudowords were not included in the model, since the uniqueness point for word identification was not controlled across word types). Typically defined as the distance (in characters) of the eye's initial fixation from the leftmost boundary of the target ROI, landing position has previously been shown to diverge when bilinguals process isolated words in different language contexts (de Leon Rodriguez et al., 2016). We focus our analyses specifically on the longer words (five characters or more), because precise fixation location becomes less critical and variable as word length decreases. We also exclude any trials in which a participant did not fixate the word immediately prior to the target (n-1), because fixating only the preceding word would offer less information with which to plan the target word fixation. This analysis shows that in Welsh sentence contexts, bilinguals' initial fixations landed significantly further to the left within the target word than in the English sentence contexts $(b=-0.26, \mathrm{SE}=0.12 \mathrm{p}=.032)$. 
Table 2: Summary of linear mixed effects (First fixation landing position*, First fixation duration, Gaze duration, Regression Path, Total Time) and generalized mixed effects (First Pass Fixation Count, Total Fixation Count) regression analyses as a function of the language context (LanguageContext) and whether the target word was a cognate or a pseudoword (Lexicality).

\begin{tabular}{|c|c|c|c|c|}
\hline & Estimate & Std. Error & $\mathrm{t}$ value & $\mathrm{p}$ \\
\hline \multicolumn{5}{|l|}{ First Pass Fixation Count } \\
\hline (Intercept) & 0.47 & 0.04 & 11.46 & $<.001$ \\
\hline LanguageContext & 0.04 & 0.02 & 1.97 & 0.049 \\
\hline Lexicality & 0.44 & 0.02 & 19.32 & $<.001$ \\
\hline LanguageContext $*$ Lexicality & -0.09 & 0.05 & -2.06 & 0.039 \\
\hline \multicolumn{5}{|l|}{ First fixation duration } \\
\hline (Intercept) & 5.44 & 0.02 & 289.47 & 0.000 \\
\hline LanguageContext & 0.05 & 0.02 & 2.41 & 0.016 \\
\hline Lexicality & 0.14 & 0.01 & 10.01 & $<.001$ \\
\hline LanguageContext $*$ Lexicality & -0.05 & 0.02 & -1.89 & 0.059 \\
\hline \multicolumn{5}{|l|}{ Gaze duration } \\
\hline (Intercept) & 5.81 & 0.04 & 142.15 & 0.000 \\
\hline LanguageContext & 0.09 & 0.03 & 2.99 & 0.003 \\
\hline Lexicality & 0.50 & 0.04 & 11.27 & $<.001$ \\
\hline LanguageContext $*$ Lexicality & -0.11 & 0.04 & -2.84 & 0.005 \\
\hline \multicolumn{5}{|l|}{ Regression Path } \\
\hline (Intercept) & 5.99 & 0.04 & 135.39 & 0.000 \\
\hline LanguageContext & 0.05 & 0.03 & 1.82 & 0.068 \\
\hline Lexicality & 0.59 & 0.05 & 12.09 & $<.001$ \\
\hline LanguageContext $*$ Lexicality & -0.19 & 0.03 & -6.00 & $<.001$ \\
\hline \multicolumn{5}{|l|}{ Total Time } \\
\hline (Intercept) & 6.12 & 0.05 & 132.19 & 0.000 \\
\hline LanguageContext & 0.05 & 0.03 & 1.86 & 0.063 \\
\hline Lexicality & 0.80 & 0.05 & 15.05 & $<.001$ \\
\hline LanguageContext $*$ Lexicality & -0.15 & 0.04 & -3.74 & $<.001$ \\
\hline \multicolumn{5}{|l|}{ Total Fixation Count } \\
\hline (Intercept) & 0.79 & 0.05 & 16.64 & $<.001$ \\
\hline LanguageContext & 0.02 & 0.02 & 0.43 & 0.67 \\
\hline Lexicality & 0.67 & 0.04 & 19.05 & $<.001$ \\
\hline LanguageContext $*$ Lexicality & -0.12 & 0.04 & -2.80 & 0.005 \\
\hline
\end{tabular}



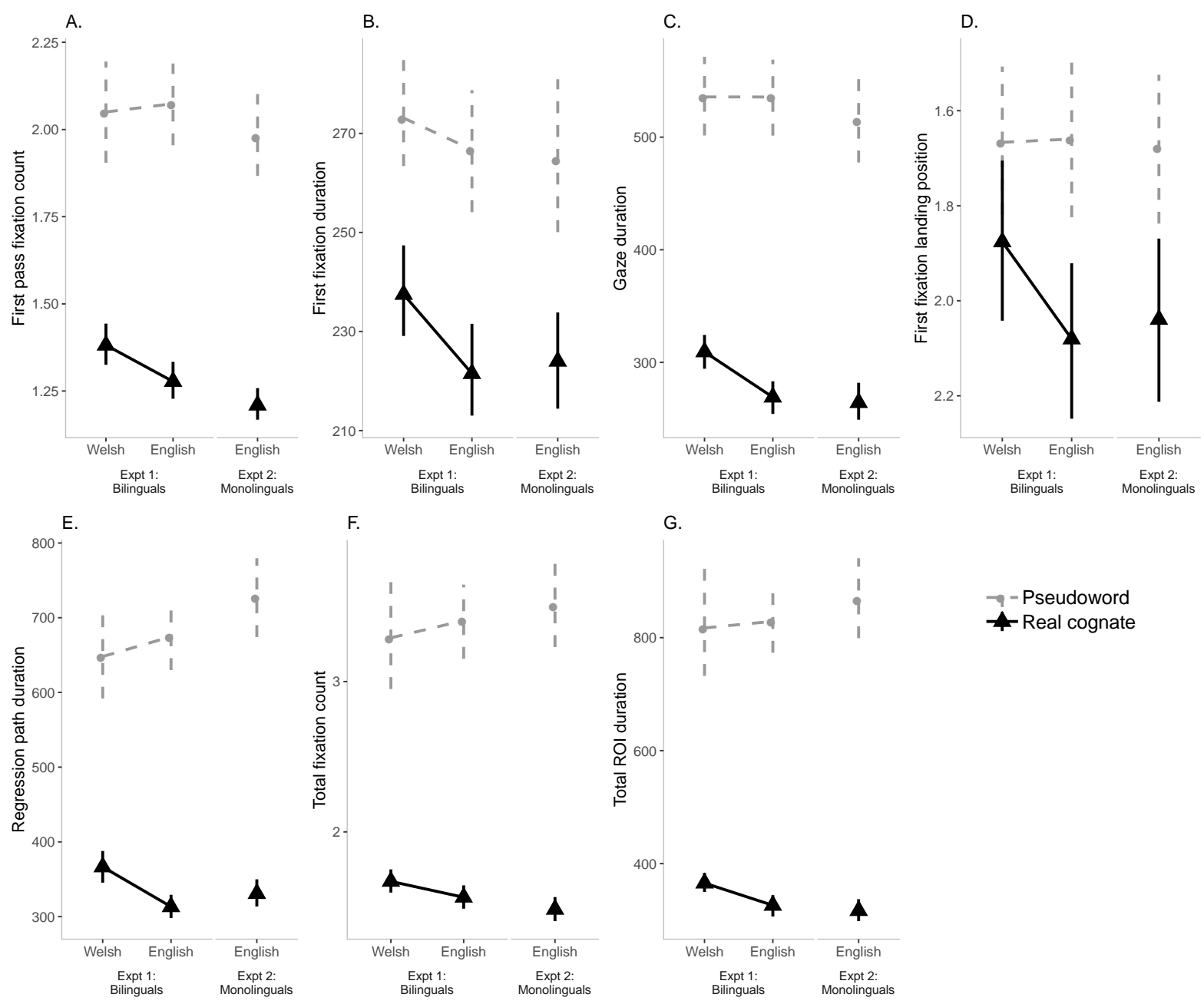

Figure 2: Effects of language context and lexicality on our key eye movement measures (Experiments 1 and 2 combined). First fixation leftwardness is represented as distance in characters from the leftmost word boundary.

Taken together, our results therefore confirm that language context indeed modulates bilinguals' eye movements, indicating smaller grain size processing in consistentorthography (Welsh) than inconsistent-orthography (English) sentences, within the same individual. The span of these effects further suggest that language modulates bilinguals' eye movements prior to the initial fixation, and persists into lexical and post-lexical processing stages. Thus, any effects of grain size accommodation are not strong enough to completely extinguish these contextual differences, though it is possible that direct comparison to monolinguals could reveal a difference from that baseline. 


\section{Experiment 2}

The results of Experiment 1 thus indicate that bilingual decoding strategies can adapt to individual language contexts. However, it remains possible that even though bilinguals change reading styles, their decoding strategy in an inconsistent orthography (e.g., English) is nevertheless affected by knowledge of the other, consistent orthography (e.g., Welsh; cf. Lallier \& Carreiras, 2017). In Experiment 2, we therefore compare our Experiment 1 Englishlanguage data (Welsh-English bilinguals reading sentences in English) to that from English monolinguals reading the same English-language sentences, to assess whether the bilinguals' English decoding strategy is characterized by relatively smaller grain size processing than English monolinguals'.

If a bilingual's grain size processing is permanently altered by knowledge of the orthotactic properties of the other, more consistent orthography (in this case Welsh), we should expect them to use smaller grain size processing in English than the monolinguals (i.e. reflecting a compromise strategy between the consistent and inconsistent orthographies). Similar to the logic outlined in relation to Experiment 1, if such an alteration affects lexical access, we expect knowledge of the consistent orthography to manifest in more first pass fixations for bilinguals than monolinguals when reading the same cognates or pseudowords in English. If such effects are modulated by specific exposure to known lexical units, then we expect these bilingual differences to manifest more strongly for the real-word cognates than for the pseudowords (Language X Lexicality interaction). Associated measures of lexical processing (first fixation duration and gaze duration) should pattern similarly with our meaures of interest.

\subsection{Method}


Members of the monolingual group $(n=49$; female $=29)$ were Bangor University students, and thus from the same community as the bilinguals, but had been raised and educated entirely through the medium of English. None reported literacy or other developmental problems. Participants in the bilingual and monolingual groups were assessed for verbal fluency and general cognitive ability. Neither verbal fluency (rapid automatized naming: $t$ $(95)=.938, p=.351 ;$ Comprehensive Test of Phonological Processing, Wagner, Torgesen, \& Rashotte, 1999) nor non-verbal IQ (Wechsler Abbreviated Scale of Intelligence $(t(95)=$ $1.674, p=.097$; WASI, Wechsler, 2006) indicated significant group differences.

\subsection{Results \& Discussion}

Track losses, skipped items and programming errors accounted for $8 \%$ data loss. The approach to data transformation and analysis was identical to that used for Experiment 1. Here, each model includes two fixed effects, both contrast-coded and centered, plus their interaction: (1) Language Group $\{$ Monolingual $=-0.5$, Bilingual $=0.5\}$ (2) Lexicality $\{$ Cognate $=-0.5$, Pseudoword $=0.5\}$.

The main pattern of findings is shown in Figure 2, with statistics provided in Table 3. As in Experiment 1, our primary measure of first pass fixation count showed effects of Lexicality, in that cognates consistently elicit smaller processing times and fewer fixations compared with pseudowords. However, participants' status as a monolingual or bilingual did not significantly affect our dependent measures, nor did it interact with Lexicality. A similar pattern of results was found in the other dependent variables. In order to quantify support for claims of equivalence between monolingual and bilingual eye movements, Table 3 also provides BIC-derived Bayesian posterior probabilities for null hypotheses as needed, assuming naïve priors (Wagenmakers, 2007). In all cases, the posterior probabilities support 
simpler models that do not distinguish between monolinguals and bilingual fixation patterns.

A post hoc analysis examining bilinguals' predictive eye movements as shown in initial

landing positions on cognates similarly revealed no significant difference between groups $(b$

$=0.03, \mathrm{p}=.83 ;$ Bayes factor $=27.99)$.

Table 3: Summary of linear mixed effects (first fixation duration, gaze duration, regression path, total time) and generalized mixed effects (first pass fixation count, total fixation count) regression analyses as a function of whether the participant was monolingual or bilingual (MonoOrBilingual) and whether the target word was a cognate or a pseudoword (Lexicality).

\begin{tabular}{|c|c|c|c|c|c|}
\hline & Estimate & Std. Error & t value & $\mathrm{p}$ & $\operatorname{Pr}_{B I C}\left(H_{0} \mid \mathrm{D}\right)$ \\
\hline \multicolumn{6}{|l|}{ First Pass Fixation Count } \\
\hline $\begin{array}{l}\text { (Intercept) } \\
\text { LanguageContext }\end{array}$ & 0.43 & 0.04 & 11.01 & $<.001$ & \\
\hline LanguageContext & 0.05 & 0.03 & 1.57 & 0.12 & 0.95 \\
\hline Lexicality & 0.49 & 0.02 & 20.78 & $<.001$ & \\
\hline LanguageContext $*$ Lexicality & -0.00 & 0.05 & -0.10 & 0.92 & 0.99 \\
\hline \multicolumn{6}{|l|}{ First fixation duration } \\
\hline (Intercept) & 5.42 & 0.02 & 304.44 & 0.000 & \\
\hline LanguageContext & 0.00 & 0.03 & 0.02 & 0.98 & 0.99 \\
\hline Lexicality & 0.16 & 0.02 & 9.39 & $<.001$ & \\
\hline LanguageContext $*$ Lexicality & 0.02 & 0.03 & 0.70 & 0.49 & 0.98 \\
\hline \multicolumn{6}{|l|}{ Gaze duration } \\
\hline (Intercept) & 5.75 & 0.04 & 150.76 & 0.000 & \\
\hline LanguageContext & 0.05 & 0.04 & 1.25 & 0.22 & 0.97 \\
\hline Lexicality & 0.54 & 0.05 & 11.17 & $<.001$ & \\
\hline LanguageContext $*$ Lexicality & 0.04 & 0.04 & 1.07 & 0.29 & 0.98 \\
\hline \multicolumn{6}{|l|}{ Regression Path } \\
\hline (Intercept) & 5.99 & 0.04 & 145.41 & 0.000 & \\
\hline LanguageContext & -0.05 & 0.04 & -1.51 & 0.13 & 0.96 \\
\hline Lexicality & 0.69 & 0.05 & 13.02 & $<.001$ & \\
\hline LanguageContext $*$ Lexicality & -0.02 & 0.04 & -0.35 & 0.28 & 0.99 \\
\hline \multicolumn{6}{|l|}{ Total Time } \\
\hline (Intercept) & 6.09 & 0.04 & 140.87 & 0.000 & \\
\hline LanguageContext & 0.01 & 0.04 & 0.29 & 0.85 & 0.99 \\
\hline Lexicality & 0.90 & 0.06 & 16.12 & $<.001$ & \\
\hline LanguageContext $*$ Lexicality & -0.06 & 0.05 & -1.08 & 0.28 & 0.97 \\
\hline \multicolumn{6}{|l|}{ Total Fixation Count } \\
\hline (Intercept) & 0.78 & 0.04 & 18.79 & $<.001$ & \\
\hline LanguageContext & 0.02 & 0.04 & 0.36 & 0.75 & 0.99 \\
\hline Lexicality & 0.76 & 0.04 & 17.59 & $<.001$ & \\
\hline LanguageContext $*$ Lexicality & -0.07 & 0.05 & -1.82 & 0.07 & 0.96 \\
\hline
\end{tabular}




\section{General Discussion}

Readers decode words using orthographic grain sizes that are determined by the consistency of letter-to-sound mapping in their language(s) (e.g., Davies et al., 2007; Rau et al., 2015; Ziegler et al., 2001; Ziegler \& Goswami, 2005). Thus, reading a given language will typically require larger grain size when the mapping is less consistent. However, little is known about decoding in bilinguals, who must acquire distinct sets of letter-to-sound mappings in each of their languages. Here, we conducted the first examination of word decoding in sentence contexts for adult bilinguals fluent in both consistent (Welsh) and inconsistent (English) orthographies. We aimed to investigate whether their decoding is better characterised as a context-dependent deployment of two distinct strategies (small- and large-grain size), or a context-invariant deployment of a single 'compromise' strategy. We also compared bilinguals' English-language fixation patterns to a monolingual baseline, to see whether bilinguals' grain size when reading an inconsistent orthography (English) is decreased by their experience reading a consistent orthography (Welsh); this is also a way to assess the top-down/context-driven deployment of distinct modes of processing more generally.

In Experiment 1, we recorded eye-movements as adult, fluent Welsh-English bilinguals read Welsh (consistent orthography) and English (inconsistent orthography) sentences containing cognates or pseudowords, which were closely matched and orthotactically legal in both languages. Although there are many interdependent ways to quantify eye movement patterns, we identified first pass fixation count as the clearest test of grain size differences: because readers process only a small chunk with each fixation, smaller grain-size reading strategies require more fixations per word. In this critical measure, we show that readers fixated the same orthographic string more often when it appeared in a Welsh sentence context 
than in an English sentence context, and this difference was greater for real words than for pseudowords. That is, despite identical visual input corresponding to shared orthographic, phonological, and semantic representations in both languages, lexical access proceeded according to an apparently language-specific reading strategy, and was further contingent upon known orthographic sequences. Consistent with our expectations, this pattern of results was also found in other indices of lexical access (first fixation duration and gaze duration). It also emerged in later measures associated with semantic integration and reanalysis (total fixation time, counts and regression path). These data suggest that the orthographic properties of bilinguals' languages modulates grain size from the earliest stages of lexical access, which then cascades to post-lexical processes, extending the conclusions that can be made from a small number of behavioural and neurimaging studies (Lallier et al., 2013; Das et al., 2011; Jamal et al., 2012; Mershyan \& Hernandez, 2016). Indeed, language context appears to modulate the earliest moments of target word processing, even prior to the initial fixation: our post-hoc analysis showed that bilinguals' initial fixations tend to land closer to the first character of a word when it occurs in a consistent orthography (Welsh) than when it occurs in an inconsistent orthography (English), thus extending previous findings (de Leon Rodriguez et al., 2016) to a more naturalistic sentence reading context.

Experiment 2 provides further evidence for the functional separation of decoding strategies in bilinguals' languages: when reading English sentences, Welsh-English bilinguals' first pass fixations were comparable to those of English monolinguals. An identical pattern of results was found across all other measures (both early and late), and no significant difference emerged in first fixation landing position. Thus, at least in the case of early, fluent bilingualism, in which both languages are being used on a daily basis, we find no evidence that knowledge of a consistent orthography alters decoding in the inconsistent orthography. 
How might we incorporate this evidence for context-based modulation of decoding styles into a model of bilingual reading? We propose a step-by-step account of bilingual word decoding in the section below.

\subsection{Bilingual word decoding in sentence reading}

Adopting the BIA+ (Dijkstra \& van Heuven, 2002) as a basic framework, we propose a circuit governing language-specific visual-orthographic processing, structured as in Figure 3. The sublexical levels consist of individual graphemes and phonemes, respectively. The lexical level representations combine these into larger units; each unit is generally assumed to correspond to a single known word in a single language (e.g. a Welsh/English bilingual would have separate orthographic wordforms for camelwelsh and camelEnglish; Cai, Pickering, \& Branigan, 2011; Hartsuiker \& Pickering, 2008; Schoonbaert, Hartsuiker, \& Pickering, 2007), but layers between these points also contain frequently cooccurring sublexical sequences such as syllables or onsets, acquired through repeated exposure (cf Seidenberg \& McClelland, 1989). 
Inconsistent orthography (English)

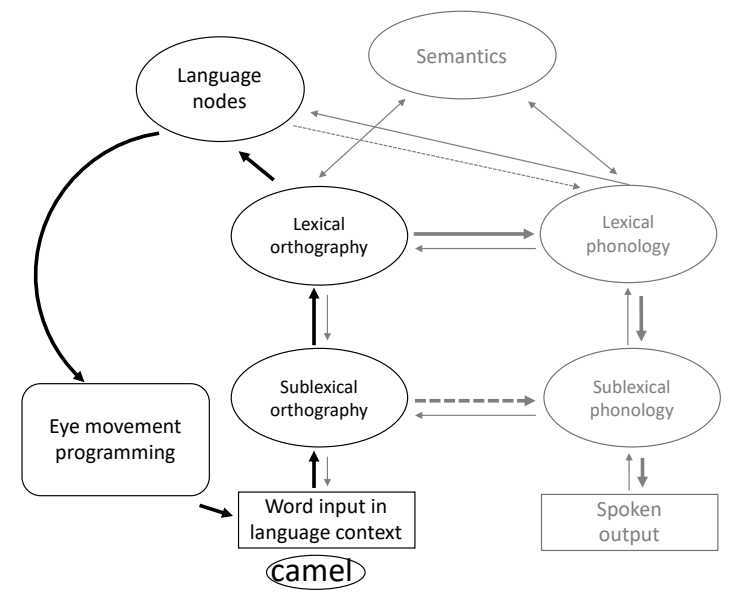

Consistent orthography (Welsh)

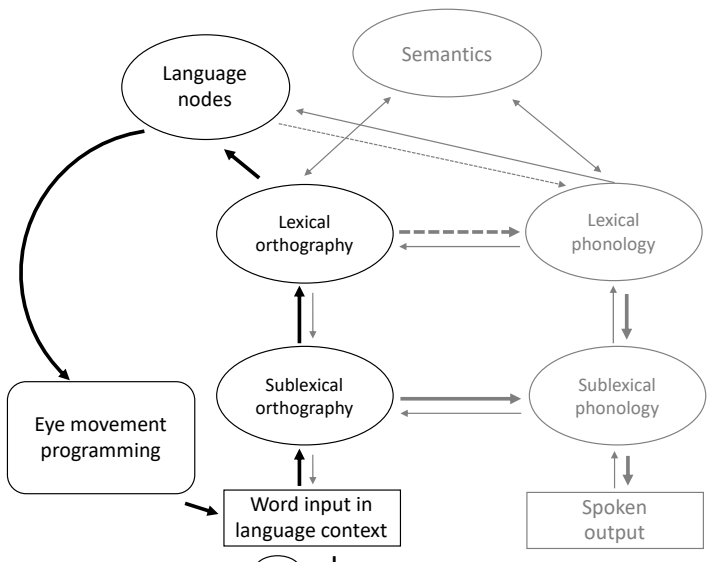

\section{Pseudowords}

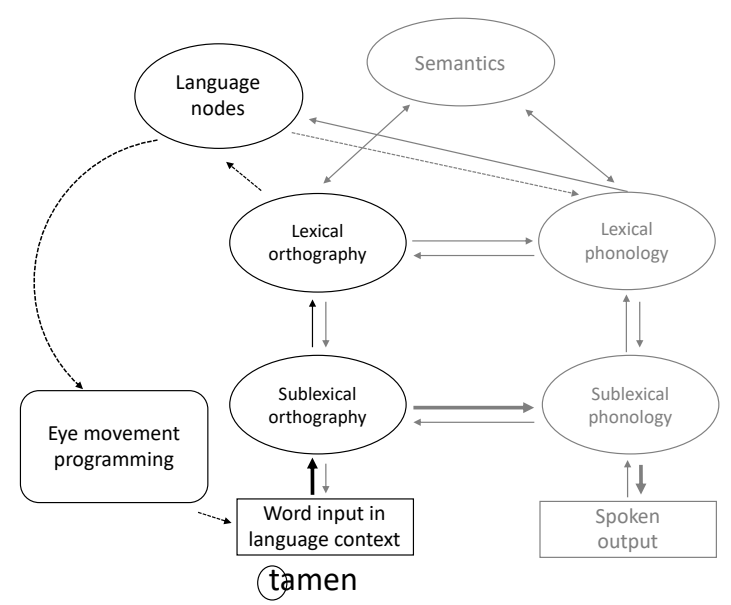

Figure 3. Schematic model representing top-down contextual influences on bilingual decoding style. Thin grey arrows represent pre-existing links instantiated in the BIA+. Note that arrow direction here indicates processing stages for explanatory purposes only, and we make no assumptions concerning feedback vs. feedforward processes. Adapted from Dijkstra and van Heuven (2002).

First, our data suggest that language context biases the earliest stages of lexical processing, manifesting in language-based differences even in the location and duration of a reader's first fixation. Language context therefore appears to modulate early word analysis on a predictive basis, during parafoveal preview of the word. In Figure 3, we assume that such effects 
emerge from the larger sentence context: prior activation in the lexical orthographic layer persistently activates the relevant language node, which then biases the initial perception or assumed grain size for the next word (see also Schwartz \& Kroll, 2006; Libben \& Titone, 2009 for a similar argument in relation to bilingual lexical access); this is illustrated as the black arrow from the language node to the input, reflecting biases in the way that the input is taken in.

Based on our pseudoword fixation patterns, we assume that the default oculomotor planning for any string of letters reflects a particularly small grain size (Buetler et al., 2014; Clark \& O’Regan, 1998; de León Rodríguez, 2016), but input from the language nodes to eye movement programming may increase the grain size. In a language with less consistent orthography to phonology mapping (e.g., English), there may be a general benefit to processing more letters in parallel - reflected in fewer fixations - increasing input to the lexical orthographic layer where they can be integrated. This could be accomplished by programming a larger visual grain, such as a single fixation nearer to the visual center of the word (cf. Vitu, O’Regan, \& Mittau, 1990; Tao-N'Dre, Castel, \& Vitu, 2013), a pattern also suggested by our data. We further assume that such greater activation of the lexical orthographic layer increases its contribution to the orthography to phonology mapping (top left panel in Figure 3, indicated by solid grey arrow from lexical orthography to phonology, although our data do not directly speak to the point). In a language with more consistent orthography-to-phonology mapping (e.g., Welsh), smaller grain sizes - reading fewer letters at a time - may allow the sublexical pathway to incrementally activate phonology before the lexical pathway fully comes online (top right panel in Figure 3, top right panel, indicated by solid grey arrow from sublexical orthography to phonology). 
Finally, if bottom-up activation only minimally activates the learned representations in the 'lexical' orthographic layer (e.g. pseudowords), orthographic-to-phonological activation must primarily flow through the sublexical pathway. In this case, representations in the lexical orthographic layer are not strongly activated and our data show evidence of very small grain sizes that do not differ between languages (cf de León Rodríguez, 2016), consistent with an account in which pseudoword processing involves sublexical analysis (Buetler et al., 2014). We therefore assume that the language-specific eye movement programming seen for word stimuli depends on activation specifically in the lexical orthographic layer, which is missing for pseudowords. In all contexts, we further assume that activation flowing through sublexical orthographic to lexical orthographic representations can replenish this link, affecting the planning of further eye movements, within and between words.

Note that the activations in each level need not be all or none. For instance, minimally processing a distractor in a letter-detection task (e.g. Lallier et al., 2013) may not activate language nodes as strongly as processing a meaningful sentence. In such contexts, language node activation may reflect something more like an experience-based Bayesian prior that incorporates the probabilities of each language in that person's word processing experience (cf. Lallier \& Carreiras, 2017; Lallier et al., 2013, 2015). Put another way, word decoding with minimal contextual influence would result in a decoding strategy reflecting a hybrid of the orthotactic properties of both languages, encapsulated in the recent 'bilingual grain size accommodation hypothesis' (Lallier \& Carreiras, 2017).

Given that current connectionist models of reading (cf Seidenberg \& McClelland, 1989) almost exclusively describe monolingual orthography-to-phonology mapping, the findings observed in this study prompt the question: how could they address the challenge of disparate 
mappings in multiple languages? To a large extent, these models should be able to accommodate languages with different regularities in much the same way that they address regularities and exceptions within a single language: mapping via hidden units. However, our finding of distinctive fixation patterns for the same orthographic strings in two different language contexts suggests that the mapping must somehow be sensitive to the larger context in which a string appears. One potential source of difference may be external to such models: timing of input activations. To account for the current data, a connectionist reading model could plausibly implement staggered input activation; leveraging timing differences in the input to distinguish language-appropriate mappings. It would however still need to assume some mechanism by which these input timing differences could be achieved.

Finally, the question arises as to whether our data can inform the debate on language nonselective lexical access in bilingualism (cf. Kroll \& Ma, 2017). Our findings appear to support a language-selective account of sentence reading in biasing contexts (e.g., Libben \& Titone, 2009). However, we remain cautious not to over-interpret the current findings, since the deployment of different decoding strategies is restricted to orthography-to-phonology mapping, and does not necessarily preclude lexical co-activation in sentence processing (van Assche et al., 2011). Theoretically, activation of a lexical entry in a shared bilingual orthographic lexicon could trigger a language-specific decoding strategy for production without necessarily inhibiting activation of related lexical entries and corresponding semantic information from the other language.

\section{Conclusion}

Literate bilinguals learn to read in two orthographies, often with varying degrees of consistency in mapping orthography to phonology. Our study aimed to examine how 
bilinguals accomplish this feat using eye-tracking methods to analyse sentence reading in Welsh and in English contexts, respectively representing consistent and inconsistent orthographies. Our data show that bilinguals flexibly adapt their reading strategy according to the language context; applying smaller grain size for word analysis when reading sentences in the consistent compared with the inconsistent orthography. We also show that in sentence reading, bilinguals' decoding strategies are largely indistinguishable from their monolingual peers. Taken together our findings show that bilinguals retain sensitivity to the independent phonological structure of each language, which continues to affect their reading strategies in adulthood (Ziegler \& Goswami, 2005), and allows a flexible, language-specific approach to reading. Further research is now required to elucidate the characteristics of bilinguals' decoding strategies across development, and in different (e.g., unbalanced) types of bilingual populations.

\section{References}

Altarriba, J., Bauer, L. M., \& Benvenuto, C. (1999). Concreteness, context availability, and imageability ratings and word associations for abstract, concrete, and emotion words. Behavior Research Methods, Instruments, \& Computers, 31(4), 578-602.

Baayen, R., Piepenbrock, R., \& Gulikers, L. (1995). CELEX2 LDC96L14. Web Download. Philadelphia: Linguistic Data Consortium.

Ball, M. J., \& Jones, G. E. (1984). Welsh phonology: Selected readings. University of Wales Press.

Bates, D., Maechler, M., Bolker, B., \& Walker, S. (2016). lme4: Linear mixed-effects models using Eigen and S4. 2014. R package version 1.1-7. Google Scholar.

Barr, D.J., Levy, R., Scheepers, C., \& Tilly, H. J. (2013). Random effects structure for confirmatory hypothesis testing: Keep it maximal.Journal of Memory and Language, 68, $255-278$.

Cai, Z. G., Pickering, M. J., Yan, H., \& Branigan, H. P. (2011). Lexical and syntactic representations in closely related languages: Evidence from Cantonese-Mandarin bilinguals. Journal of Memory and Language, 65(4), 431-445. 
Caravolas, M., Lervåg, A., Defior, S., Seidlová Málková, G., \& Hulme, C. (2013). Different patterns, but equivalent predictors, of growth in reading in consistent and inconsistent orthographies. Psychological science, 24(8), 1398-1407.

Caravolas, M., Lervåg, A., Mousikou, P., Efrim, C., Litavský, M., Onochie-Quintanilla, E., ... \& Seidlová-Málková, G. (2012). Common patterns of prediction of literacy development in different alphabetic orthographies. Psychological science, 23(6), 678-686.

Casaponsa, A., Carreiras, M., \& Duñabeitia, J. A. (2014). Discriminating languages in bilingual contexts: the impact of orthographic markedness. Frontiers in psychology, 5, 424.

Casaponsa, A., Carreiras, M., \& Duñabeitia, J. A. (2015). How do bilinguals identify the language of the words they read?. Brain research, 1624, 153-166.

Casaponsa, A., \& Duñabeitia, J. A. (2016). Lexical organization of language-ambiguous and language-specific words in bilinguals. The Quarterly Journal of Experimental Psychology, $69,589-604$.

Das, T., Padakannaya, P., Pugh, K. R., \& Singh, N. C. (2011). Neuroimaging reveals dual routes to reading in simultaneous proficient readers of two orthographies. Neuroimage, 54, $1476-1487$.

Davies, R., Cuetos, F., \& Glez-Seijas, R. M. (2007). Reading development and dyslexia in a transparent orthography: A survey of Spanish children. Annals of dyslexia, 57(2), 179-198.

Declerck, M., Snell, J., \& Grainger, J. (2017). On the role of language membership information during word recognition in bilinguals: Evidence from flanker-language congruency effects. Psychonomic bulletin \& review, 1-6.

de León Rodríguez, D., Buetler, K. A., Eggenberger, N., Preisig, B. C., Schumacher, R., Laganaro, M., ... \& MÜRI, R. M. (2016). The modulation of reading strategies by language opacity in early bilinguals: an eye movement study. Bilingualism: Language and Cognition, 19, 567-577.

Dijkstra, T., \& Van Heuven, W. J. (2002). The architecture of the bilingual word recognition system: From identification to decision. Bilingualism: Language and cognition, 5(3), 175197.

Dijkstra, T., \& Van Heuven, W. J. (1998). The BIA model and bilingual word recognition. In J. Grainger \& A. M. Jacobs (eds.), Localist connectionist approaches to human cognition, pp. 189-225. Mahwah, NJ: Lawrence Erlbaum Associates.

Dijkstra, T., Van Heuven, W. J., \& Grainger, J. (1998). Simulating cross-language competition with the bilingual interactive activation model. Psychologica Belgica.

Duncan, L. G., Seymour, P. H., \& Hill, S. (1997). How important are rhyme and analogy in beginning reading?. Cognition, 63(2), 171-208. 
Ellis, N. C., \& Hooper, A. M. (2001). Why learning to read is easier in Welsh than in English: Orthographic transparency effects evinced with frequency-matched tests. Applied Psycholinguistics, 22(4), 571-599.

Ellis, N. C., Natsume, M., Stavropoulou, K., Hoxhallari, L., DAAL, V. H., Polyzoe, N., ... \& Petalas, M. (2004). The effects of orthographic depth on learning to read alphabetic, syllabic, and logographic scripts. Reading Research Quarterly, 39(4), 438-468.

Ellis, N. C., O’Dochartaigh, C., Hicks, W., Morgan, M., \& Laporte, N. (2001). Cronfa Electroneg o Gymraeg (CEG): a 1 million word lexical database and frequency count for Welsh. URL: www. bangor. ac. uk/canolfanbedwyr/ceg. php. en.

Elston-Güttler, K. E., Paulmann, S., \& Kotz, S. A. (2005). Who's in control? Proficiency and L1 influence on L2 processing. Journal of cognitive neuroscience, 17(10), 1593-1610.

Goswami, U., Gombert, J. E., \& de Barrera, L. F. (1998). Children's orthographic representations and linguistic transparency: Nonsense word reading in English, French, and Spanish. Applied Psycholinguistics, 19(1), 19-52.

Goswami, U., Ziegler, J. C., Dalton, L., \& Schneider, W. (2003). Nonword reading across orthographies: How flexible is the choice of reading units?. Applied Psycholinguistics, 24, 235-247.

Grainger, J., \& Beauvillain, C. (1987). Language blocking and lexical access in bilinguals. The Quarterly Journal of Experimental Psychology Section A, 39, 295-319.

Harm, M. W., \& Seidenberg, M. S. (1999). Phonology, reading acquisition, and dyslexia: insights from connectionist models. Psychological review, 106, 491.

Hartsuiker, R.J., \& Pickering, M.J. (2008). Language integration in bilingual sentence production. Acta Psychologica, 128, 479-489.

Jamal, N. I., Piche, A. W., Napoliello, E. M., Perfetti, C. A., \& Eden, G. F. (2012). Neural basis of single-word reading in Spanish-English bilinguals. Human Brain Mapping, 33, 235245.

Kroll, J.F., \& Ma, F. (2017). The Bilingual Lexicon. In Fernandez, E.M., \& Cairns, H.S. (Eds). The Handbook of Psycholinguistics. Wiley.

Lallier, M., \& Carreiras, M. (2017). Cross-linguistic transfer in bilinguals reading in two alphabetic orthographies: The grain size accommodation hypothesis. Psychonomic bulletin \& review, 1-16.

Lallier, M., Carreiras, M., Tainturier, M. J., Savill, N., \& Thierry, G. (2013). Orthographic transparency modulates the grain size of orthographic processing: behavioral and ERP evidence from bilingualism. Brain research, 1505, 47-60.

Lallier, M., Acha, J., \& Carreiras, M. (2016). Cross-linguistic interactions influence reading development in bilinguals: a comparison between early balanced French-Basque and Spanish-Basque bilingual children. Developmental science, 19(1), 76-89. 
Lallier, M., Valdois, S., Lassus-Sangosse, D., Prado, C., \& Kandel, S. (2014). Impact of orthographic transparency on typical and atypical reading development: evidence in FrenchSpanish bilingual children. Research in developmental disabilities, 35(5), 1177-1190.

Landerl, K. (2000). Influences of orthographic consistency and reading instruction on the development of nonword reading skills. European journal of psychology of education, 15(3), 239.

Landerl, K., Wimmer, H., \& Frith, U. (1997). The impact of orthographic consistency on dyslexia: A German-English comparison. Cognition, 63(3), 315-334.

Libben, M. R., \& Titone, D. A. (2009). Bilingual lexical access in context: evidence from eye movements during reading. Journal of Experimental Psychology: Learning, Memory, and Cognition, 35(2), 381.

McClelland, J. L., \& Rumelhart, D. E. (1981). An interactive activation model of context effects in letter perception: I. An account of basic findings. Psychological review, 88(5), 375.

Marinus, E., Nation, K., \& de Jong, P. F. (2015). Density and length in the neighborhood: Explaining cross-linguistic differences in learning to read in English and Dutch. Journal of Experimental Child Psychology, 139, 127-147.

Meschyan, G., Hernandez, A.E. (2016). Impact of language proficiency and orthographic transparency on bilingual word reading: An fMRI investigation. NeuroImage, 29, pp. 11351140.

Paulesu, E., McCrory, E., Fazio, F., Menoncello, L., Brunswick, N., Cappa, S. F., ... \& Pesenti, S. (2000). A cultural effect on brain function. Nature neuroscience, 3(1), 91.

Pollatsek, A., \& Rayner, K. (1990). Eye movements and lexical access in reading. In D. A. Balota, G. B. Flores d'Arcais, \& K. Rayner (Eds.), Comprehension processes in reading (pp. 143 - 164). Hillsdale, NJ: Erlbaum.

Pynte, J. (1996). Lexical control of within-word eye movements. Journal of Experimental Psychology: Human Perception and Performance, 22, 958.

Rau, A. K., Moll, K., Snowling, M. J., \& Landerl, K. (2015). Effects of orthographic consistency on eye movement behavior: German and English children and adults process the same words differently. Journal of experimental child psychology, 130, 92-105.

Rayner, K., \& Pollatsek, A. (1987). Eye movements in reading: A tutorial review. In M. Coltheart (Ed.), Attention and Performance. Vol 12, pp. 327-362. London: Erlbaum.

Schoonbaert, S., Hartsuiker, R.J., \& Pickering, M.J. (2007). The representation of lexical and syntactic information in bilinguals: Evidence from syntactic priming. Journal of Memory and Language, 56, 153-171

Seidenberg, M. S., \& McClelland, J. L. (1989). A distributed, developmental model of word recognition and naming. Psychological review, 96, 523. 
Treiman, R., Mullennix, J., Bijeljac-Babic, R., \& Richmond-Welty, E. D. (1995). The special role of rimes in the description, use, and acquisition of English orthography. Journal of Experimental Psychology: General, 124, 107.

Van Assche, E., Drieghe, D., Duyck, W., Welvaert, M., \& Hartsuiker, R. J. (2011). The influence of semantic constraints on bilingual word recognition during sentence reading. Journal of Memory and Language, 64, 88-107.

Van Heuven, W. (2016). Pseudo (a pseudoword generator).

http://www.psychology.nottingham.ac.uk/staff/wvh/internal/research/pseudo/

Vitu, F., O’Regan, J. F., \& Mittau, M. (1990). Optimal landing position in reading isolated words and continuous text. Perception \& Psychophysics, 47, 583-600.

Yao-N'Dré, M., Castel, E., \& Vitu, F. (2013). The Optimal Viewing Position effect in the lower visual field. Vision Research, 76, 114-123. Zhang, S., \& Thompson, N. (2004).

Wagenmakers, E. J. (2007). A practical solution to the pervasive problems ofp values. Psychonomic bulletin \& review, 14, 779-804.

Wimmer, H., \& Goswami, U. (1994). The influence of orthographic consistency on reading development: Word recognition in English and German children. Cognition, 51, 91-103.

Ziegler, J. C., \& Goswami, U. (2005). Reading acquisition, developmental dyslexia, and skilled reading across languages: a psycholinguistic grain size theory. Psychological bulletin, 131,3 .

Ziegler, J. C., Perry, C., Ma-Wyatt, A., Ladner, D., \& Schulte-Körne, G. (2003).

Developmental dyslexia in different languages: Language-specific or universal?. Journal of experimental child psychology, 86, 169-193.

Ziegler, J. C., Perry, C., Jacobs, A. M., \& Braun, M. (2001). Identical words are read differently in different languages. Psychological science, 12, 379-384. 
Appendix A

\begin{tabular}{|c|c|}
\hline 1 & $\begin{array}{l}\text { She looked inside the bag / bam for her purse } \\
\text { Edrychodd yn y bag / bam am ei phwrs }\end{array}$ \\
\hline 2 & $\begin{array}{l}\text { Your brother is carrying a bar / lar made of iron, said Martin } \\
\text { Mae dy frawd yn cario bar / lar haearn, meddai Martin }\end{array}$ \\
\hline 3 & $\begin{array}{l}\text { For his birthday, Robert received a bat / wat to play cricket } \\
\text { Ar ei benblwydd, cafodd Robert bat /wat } i \text { chwarae criced }\end{array}$ \\
\hline 4 & $\begin{array}{l}\text { At the back of the shop, there's a bin / bon to be emptied } \\
\text { Yng nghefn y siop, mae yna bin / bon } i^{\prime} w \text { wagio }\end{array}$ \\
\hline 5 & $\begin{array}{l}\text { Elen looked at the can / san of dog food in the shop } \\
\text { Edrychodd Elen ar y can / san ofwyd ci yn y siop }\end{array}$ \\
\hline 6 & $\begin{array}{l}\text { She reached for the cap / dap that hung on the hook } \\
\text { Estynodd am y cap / dap a oedd ar y bachyn }\end{array}$ \\
\hline 7 & $\begin{array}{l}\text { She enjoyed cleaning the car / cal when it was muddy } \\
\text { Roedd hi'n mwynhau golchi'r car / cal pan oedd yn fwdlyd }\end{array}$ \\
\hline $8 *$ & $\begin{array}{l}\text { When she regained consciousness, the van / han had disappeared } \\
\text { Pan oedd yn ymwybodol eto, roedd y fan / han wedi diflannu }\end{array}$ \\
\hline $9 *$ & $\begin{array}{l}\text { She used a brush / brosh to undo the knots in her hair } \\
\text { Defnyddiodd brwsh / brosh } \text { i dadglymu ei gwallt }\end{array}$ \\
\hline 10 & $\begin{array}{l}\text { The old lady enjoyed ham / hom and cheese for lunch } \\
\text { Roedd yr hen ddynes yn hoffi ham / hom a chaws I ginio }\end{array}$ \\
\hline 11 & $\begin{array}{l}\text { Whenever they had a picnic, he liked to have jam / jat on his sandwiches } \\
\text { Pan aethant am bicnic, roedd o'n hoffi cael jam / jat ar ei fechdanau }\end{array}$ \\
\hline 12 & $\begin{array}{l}\text { On the table was a jar / jur and it was completely empty } \\
\text { Ar y bwrdd roedd jar / jur ac roedd yn hollol wag }\end{array}$ \\
\hline 13 & $\begin{array}{l}\text { He had prepared well, with a map / mip and compass in his bag } \\
\text { Roedd o wedi paratoi yn dda, gyda map / mip a chwmpawd yn ei fag }\end{array}$ \\
\hline 14 & $\begin{array}{l}\text { In the story, the wizzard had a mat / mal that could fly } \\
\text { Yn y stori, roedd gan y dewin mat / mal a oedd yn hedfan }\end{array}$ \\
\hline 15 & $\begin{array}{l}\text { As an efficient worker, he used a mop / nop to clean the floor } \\
\text { Fel gweithiwr effeithlon, defnyddiodd mop / nop I lanhau'r llawr }\end{array}$ \\
\hline 16 & $\begin{array}{l}\text { To her disappointment, she had just one more peg / ped to hang up the washing } \\
\text { At ei siom, roedd ganddi ond un peg / ped ar ôl i roi'r dillad ar y lein }\end{array}$ \\
\hline 17 & $\begin{array}{l}\text { The children went to see the clown / slown, and he was very funny } \\
\text { Fe aeth y plant } i \text { weld y clown / slown, ac roedd yn ddoniol iawn }\end{array}$ \\
\hline 18 & $\begin{array}{l}\text { Looking at the old coat, she used a pin / pid to raise the hem } \\
\text { Gan edrych ar yr hen gôt, mi ddefnyddiodd pin / pid i godi'r hem }\end{array}$ \\
\hline 19 & $\begin{array}{l}\text { When she joined the club, she learned a new set / sep of rules } \\
\text { Pan ymunodd a'r clwb, mi ddysgodd set / sep newydd o reolau }\end{array}$ \\
\hline 20 & $\begin{array}{l}\text { She wanted to wash her face, but the tap / tep was broken } \\
\text { Roedd hi eisiau golchi'i gwyneb, ond roeddy tap / tep wedi torri }\end{array}$ \\
\hline $21 *$ & $\begin{array}{l}\text { He ran as fast as he could, but the bus / bes had left already } \\
\text { Fe redodd nerth ei draed, ond roedd y bws / bes wedi gadael yn barod }\end{array}$ \\
\hline 22 & $\begin{array}{l}\text { He wore a wig / wid to hide his bald spot } \\
\text { Fe wisgodd wig / wid i orchuddio'i fan moel }\end{array}$ \\
\hline 23 & $\begin{array}{l}\text { They went inside when they saw that a storm / starm was coming } \\
\text { Aethant i fewn pan welsant fod yna storm / starm ar ei ffordd }\end{array}$ \\
\hline 24 & She could see properly with a clip / clin to hold back her hair \\
\hline
\end{tabular}




\begin{tabular}{|c|c|}
\hline & Roedd hi'n gallu gweld yn iawn gyda clip / clin i gadw'i gwallt yn ôl \\
\hline $25 *$ & $\begin{array}{l}\text { John chose an old film / folm that was in black and white } \\
\text { Dewisodd John hen ffilm / ffolm a oedd mewn du a gwyn }\end{array}$ \\
\hline $26 *$ & $\begin{array}{l}\text { On top of the castle, a flag / flig waved in the strong wind } \\
\text { Ar ben y castell, roedd fflag / fflig yn chwifio yn y gwynt cryf }\end{array}$ \\
\hline 27 & $\begin{array}{l}\text { As night fell, a lamp / lalp shone on the kitchen table } \\
\text { Wrth iddi dywyllu, roedd lamp / lalp yn disgleirio ar y bwrdd gegin }\end{array}$ \\
\hline $28 *$ & $\begin{array}{l}\text { Edwin was late, but he got a lift / laft to the airport just in time } \\
\text { Roedd Edwin yn hwyr, ond cafodd lifft / lafft i'r faes awyr jest mewn amser }\end{array}$ \\
\hline 29 & $\begin{array}{l}\text { Around Christmas time, the post / dost is always very busy } \\
\text { O gwmpas y Nadolig, mae'r post / dost o hyd yn brysur iawn }\end{array}$ \\
\hline $30 *$ & $\begin{array}{l}\text { He was very busy, but the sink / sind was dirty and needed to be cleaned } \\
\text { Roedd o'n brysur iawn, ond roedd y sinc / sind yn fudr ac angen ei lanhau }\end{array}$ \\
\hline $31 *$ & $\begin{array}{l}\text { In hot countries, it's possible you will see a crocodile / drocadole swimming in the river } \\
\text { Mewn gwledydd poeth, mae'n bosib y gwelwch crocodeil / drocadole yn nofio yn yr afon }\end{array}$ \\
\hline 32 & $\begin{array}{l}\text { He needed the help of a camel / tamen to get him across the desert } \\
\text { Roedd angen help camel / tamen arno i fynd ar draws yr anialwch }\end{array}$ \\
\hline $33 *$ & $\begin{array}{l}\text { For the exam she had a pencil / pemtil and several shaperners } \\
\text { Ar gyfer yr arholiad, roedd ganddi pensal / pemptil a sawl miniwr }\end{array}$ \\
\hline 34 & $\begin{array}{l}\text { He enjoyed having a slice of lemon / demog in his drink, occasionally. } \\
\text { Roedd o'n hoffi cael sleis o lemon / demog yn ei ddiod, weithiau }\end{array}$ \\
\hline 35 & $\begin{array}{l}\text { She was proud, and made sure that her medal / gesal always shone } \\
\text { Roedd yn falch, ac yn gwneud yn siwr fod ei medal / gesal yn sgleinio bob amser }\end{array}$ \\
\hline $36 *$ & $\begin{array}{l}\text { The girl was brave, and took a bite of octopus / actiput for the first time } \\
\text { Roedd yr enneth yn ddewr, a chymerodd damed o octopws / actipwt am y tro cyntaf }\end{array}$ \\
\hline $37 *$ & $\begin{array}{l}\text { Looking over the side, he saw the dolphin / dosphan rising from the foam } \\
\text { Gan edrych dros yr ochr, fe welodd y dolffin / dosffan yn codi o'r ewin }\end{array}$ \\
\hline 38 & $\begin{array}{l}\text { The skin is the organ / artan that stretches all over the body } \\
\text { Y croen } y w^{\prime} \text { r organ / artan sy'n ymestyn ar hyd y corff }\end{array}$ \\
\hline 39 & $\begin{array}{l}\text { The children were disappointed when they saw that the panda / patga was fast asleep } \\
\text { Roedd y plant yn siomedig pan welson fod y panda / patga yn cysgu'n sownd }\end{array}$ \\
\hline 40 & $\begin{array}{l}\text { She can play the piano / pilto, but she should practice more } \\
\text { Mae hi'n chwarae'r piano / pilto, ond mi ddylie hi ymarfer mwy }\end{array}$ \\
\hline 41 & $\begin{array}{l}\text { The policeman used his radio / lapeo to call for assistance } \\
\text { Defnyddiodd y plismon ei radio / lapeo } i \text { alw am gymorth }\end{array}$ \\
\hline 42 & $\begin{array}{l}\text { In order to learn how to build a robot / sobod, he studied engineering. } \\
\text { I ddysgu sut } i \text { adeiladu robot / sobod, mi astudiodd peirianeg }\end{array}$ \\
\hline $43 *$ & $\begin{array}{l}\text { They tried to go faster, but the caravan / casolan was heavy and slow } \\
\text { Bu iddynt drio fynd yn gyflyn, ond roedd y carafan / casolan yn drwm ac yn araf }\end{array}$ \\
\hline 44 & $\begin{array}{l}\text { He was in a rush, so he only had a banana / panota for breakfast. } \\
\text { Roedd o ar frys, a chafodd ond banana / panota ar gyfer ei frecwast }\end{array}$ \\
\hline 45 & $\begin{array}{l}\text { The thief stole the camera / comasa during the concert } \\
\text { Bu i'r lleidr ddwyn y camera / comasa yn ystod y cyngerdd }\end{array}$ \\
\hline 46 & $\begin{array}{l}\text { The doctor / moctar was kind, and gave the child a lollypop } \\
\text { Roedd y doctor / moctar yn ffeind, a rhoddodd lolipop i'r plentyn }\end{array}$ \\
\hline 47 & $\begin{array}{l}\text { The child thought that her magnet / pagset was something magical } \\
\text { Roedd y plentyn yn meddwl fod ei magnet / pagset yn rhywbeth hudol }\end{array}$ \\
\hline 48 & $\begin{array}{l}\text { It's quite normal / nostal to sunbathe in July } \\
\text { Mae'n beth eithaf normal / nostal } i \text { dorheulo yn mis Gorffennaf }\end{array}$ \\
\hline
\end{tabular}




\begin{tabular}{|l|l|}
\hline 49 & $\begin{array}{l}\text { He inherited an old collection of records / necorts from his Grandfather } \\
\text { Bu iddo etifeddu hen gasgliad o records / necorts gan ei Daid }\end{array}$ \\
\hline 50 & $\begin{array}{l}\text { The girl threw her sandal / candas out of her pram } \\
\text { Taflodd yr enneth ei sandal / candas allan o'r pram }\end{array}$ \\
\hline $51^{*}$ & $\begin{array}{l}\text { When the young penguin / senguil found his father, he sheltered from the storm } \\
\text { Pan ddarganfyddodd y pengwin / sengwil ei dad, caeth gysgod rhag y storm }\end{array}$ \\
\hline 52 & $\begin{array}{l}\text { He liked eating a tomato / lomuga after picking it from the garden } \\
\text { Roedd yn hoffi bwyta tomato / lomuga ar ol ei bigo o'r ardd }\end{array}$ \\
\hline 53 & $\begin{array}{l}\text { He wanted to write, but the monitor / tonagor on his computer was broken. } \\
\text { Roedd o eisiau ysgrifennu, ond roedd y monitor / tonagor ar ei gyfrifiadur wedi torri }\end{array}$ \\
\hline 54 & $\begin{array}{l}\text { There was a painting of a pelican / delaman on the kitchen wall. } \\
\text { Roedd yna lun o pelican / delaman ar wal y gegin }\end{array}$ \\
\hline 55 & $\begin{array}{l}\text { She waited eagerly for the postman / poltmat to deliver the parcel } \\
\text { Arosodd yn eiddgar am y postman / poltmat a oedd yn anfon parsel }\end{array}$ \\
\hline 56 & $\begin{array}{l}\text { In the distance, they saw the pyramid / paromit that was ancient } \\
\text { Yn y pellter, gwelson y pyramid / paromit a oedd yn hynafol iawn }\end{array}$ \\
\hline 57 & $\begin{array}{l}\text { The boy had been driving the tractor / traston for years } \\
\text { Roeddy bachgen wedi bod yn gyrru'r tractor / traston ers blynyddoedd }\end{array}$ \\
\hline 58 & $\begin{array}{l}\text { Her mother makes her practice the clarinet / blaroner every day. } \\
\text { Mae ei mam yn ei gorfodi } i \text { ymarfer y clarinet / blaroner bob diwrnod }\end{array}$ \\
\hline 59 & $\begin{array}{l}\text { She accepted the rose, as a symbol / sombot of his love } \\
\text { Debyniodd y rhosyn, fel symbol / sombot } \text { 'i gariad }\end{array}$ \\
\hline 60 & $\begin{array}{l}\text { To keep the house tidy, they needed a system / sistel to help them clean } \\
\text { Er mwyn cadw'r ty yn daclus, roedd angen system / sistel arnynt } i \text { helpu lanhau }\end{array}$ \\
\hline
\end{tabular}

